\title{
Immunoassay of serum conjugates of cholic acid in cystic fibrosis
}

\author{
GP DAVIDSON*, MARY COREY, FREDA MORAD-HASSEL, JUDITH M \\ SONDHEIMER, D CROZIER, AND GG FORSTNER
}

From the Hospital for Sick Children, Toronto, Ontario, Canada M5G 1 X8

SUMMARY Pre- and post-prandial serum conjugates of cholic acid (SCCA) were measured by radioimmunoassay (RIA) in 83 patients with cystic fibrosis (CF), 14 of whom did not have steatorrhoea, and in 25 controls. Of the CF patients with steatorrhoea, 38\% had fasting SCCA levels greater than 3 standard deviations above mean fasting control values, whereas no CF patient without steatorrhoea had elevated fasting SCCA levels. Steatorrhoeic patients with palpable livers had higher pre- and post-prandial SCCA levels. Post-prandial SCCA levels failed to discriminate between control and CF groups however. Other serum tests of liver function, including the aspartate amino transferase, alkaline phosphatase, albumin, $\gamma$ globulin, and albumin: globulin ratio, failed to correlate with the SCCA. Changes in serum protein constituents correlated strongly with pulmonary dysfunction.

The results suggest that elevation of fasting SCCA levels in CF patients is a more sensitive indicator of liver dysfunction than other tests and is a better discriminator than post-prandial SCCA levels between normal and abnormal liver function. The test is recommended for early detection of liver dysfunction in CF patients.

The introduction in 1973 of a radioimmunoassay for conjugated cholyl bile acids in serum ${ }^{1}$ provided a more sensitive indicator of hepatic disease activity than any of the conventional tests of liver function. ${ }^{2}$ Several authors have claimed that normal and abnormal liver function can be discriminated more sharply if bile acids are measured after a meal ${ }^{3-5}$ or after intravenous infusion of bile acids, ${ }^{6}$ but Pennington et al. ${ }^{7}$ have reported that fasting serum bile acids are as sensitive as post-prandial bile acids in detecting liver disease. Earlier studies in small numbers of children with cystic fibrosis $(C F)^{8} 9$ have shown elevated fasting serum bile acids but failed to provide sufficient information to assess the usefulness of the test.

We assessed liver function in children with $\mathrm{CF}$ by measuring serum conjugates of cholic acid (SCCA) in the fasting state and 2 hours postprandially. These results were compared to conventional serum tests of liver function, aspartate amino transferase (AST), alkaline phosphatase, total and

*Present address: Adelaide Children's Hospital, North Adelaide, South Australia 5006, Australia.

Received for publication 19 September 1979 direct bilirubin, albumin, $\gamma$ globulin, and albumin: globulin ratios.

\section{Patients and methods}

We studied 83 outpatients from the CF clinic at The Hospital for Sick Children, Toronto. The diagnosis of $\mathrm{CF}$ had previously been confirmed by abnormal sweat chloride determinations ( $>60 \mathrm{mmol} / \mathrm{l}$ ). Blood was drawn after an overnight fast and again 2 hours after breakfast for estimation of SCCA levels. Liver function tests, including serum alkaline phosphatase (ALP), AST, serum protein electrophoresis, and total and direct bilirubin were measured by routine laboratory methods. The meal consisted of cereal, toast or equivalent, bacon, sausage or egg plus at least one glass of milk. Subjects or their parents were informed of the experimental nature of the study and their consent was obtained.

Sixty-nine patients had steatorrhoea. The remaining 14 had no steatorrhoea or history of prolonged diarrhoea and did not need pancreatic enzyme replacement therapy. Pancreatic function was therefore considered to be well preserved, and this group was considered separately. In 13 patients 
Table 1 Diagnosis in 25 control patients

\begin{tabular}{lr}
\hline Asthma & 12 \\
Failure to thrive & 5 \\
Familial dysplasia of lung & 2 \\
Shwachman's syndrome & 2 \\
Normal adults & 4 \\
\hline
\end{tabular}

in this group the five-day faecal fat excretion was less than $10 \%$ of intake. In the remaining patient, fat excretion was $11 \%$ but pancreatic enzyme output was found to be normal during stimulation by continuous infusion of secretin and cholecystokinin. ${ }^{10}$ Seven patients had been shown to have a normal elevation of plasma vitamin A after a standard oral dose. Four patients had had the presence of pancreatic enzymes confirmed by secretin cholecystokinin infusion, and four had normal quantities of serum pancreatic amylase demonstrated by isoelectric focusing. ${ }^{11}$ A control group of 25 subjects was obtained from hospital patients and staff who had no liver disease. They are listed in Table 1.

RADIOIMMUNOASSAY FOR SCCA

Sera were stored for not more than three weeks at $-20^{\circ} \mathrm{C}$ before evaluation. Radioimmunoassay for SCCA was performed according to the method of Simmonds et al., ${ }^{1}$ as previously described. ${ }^{12}$ The antibody was equally sensitive to taurocholate and glycocholate and did not bind deoxycholate conjugates significantly. The assay mixture contained $10 \mu \mathrm{l}$ of test serum (or appropriate dilution thereof), $100 \mu \mathrm{l}$ of rabbit antiserum diluted $1: 10$ with $0.01 \mathrm{M}$

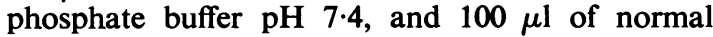
human serum diluted 1:2 with buffer from which bile salts had been extracted with charcoal (Norit A, British Drug Houses, Toronto, Canada). Tracer amounts of tritiated glycocholate (cholate- ${ }^{3} \mathrm{H}(\mathrm{G})$; $3.8 \mathrm{Ci} / \mu \mathrm{mol}$; New England Nuclear, Boston, Massachusetts, USA) were added and additional buffer to make a final volume of $0.5 \mathrm{ml}$. The $\mathrm{Ka}$ for antibody-antigen binding with glycocholate was $5.0 \times 10^{9}$. The percentage binding $\left(\mathrm{B} / \mathrm{B}_{0} \times 100\right)$ decreased linearly from 100 to $55 \%$ with a logarithmic increase in added unlabelled glycocholate from 20 to 100 pmol. Interassay variation was $8 \%(\mathrm{CV})$ over a period of eight weeks; within assay variation was $7 \cdot 7 \%(\mathrm{CV})$.

ALP, AST, serum protein electrophoresis, and serum bilirubin were measured by routine laboratory methods.

Fifty-two of the 69 patients with steatorrhoea were sufficiently old to have had pulmonary function testing. In this subgroup, simple correlations and multiple regressions were computed using the variables of pre-prandial SCCA, AST, ALP, albumin, $\gamma$ globulin and albumin:globulin ratio, forced vital capacity (FVC), 1-second forced expiratory volume $\left(F E V_{1}\right)$, mean forced expiratory flow rate during the middle half of the FVC (MMEF), and age, employing the SPSS statistical package ${ }^{13}$ and analytical methods described by Snedecor and Cochran. ${ }^{14}$ Group means were compared using Student's $t$ test.

\section{Results}

The pre-prandial SCCA levels in the 69 CF patients receiving pancreatic supplements were significantly greater than the values in the controls $(P<0.001)$ or in the $14 \mathrm{CF}$ patients not requiring pancreatic supplements $(\mathrm{P}<0.001)$ (Table 2$)$. There was no significant difference in the post-prandial SCCA levels between any of the groups. The post-prandial rise was significant in each group when pre- and post-prandial levels were compared using the paired $t$ test (Table 2).

In Figs 1 and 2 the distribution of the individual SCCA values in each group is shown for the controls, CF patients receiving enzyme therapy, and CF patients not receiving enzymes. Pre-prandial results are given in Fig. 1, post-prandial in Figure 2. The range of fasting values for control and CF patients without steatorrhoea was similar. None of these values exceeded $1.25 \mathrm{mmol} / \mathrm{l}$ or $3 \mathrm{SD}$ above the mean value for controls, whereas 26 of $69(38 \%)$ patients

Table 2 SCCA levels in controls and two groups of patients with $C F$

\begin{tabular}{|c|c|c|c|c|c|c|}
\hline & \multirow[t]{2}{*}{ No. } & \multirow[t]{2}{*}{ Age } & \multirow[t]{2}{*}{ Age range } & \multicolumn{2}{|c|}{$S C C A(\mathrm{mmol} / \mathrm{l})$} & \multirow[t]{2}{*}{$\mathbf{P} \dagger$} \\
\hline & & & & Pre-prandial & Post-prandial & \\
\hline $\begin{array}{l}\text { Control patients } \\
\text { Cystic fibrosis patients }\end{array}$ & 25 & $11 \cdot 9 \pm 11 \cdot 7$ & $1 \cdot 0-43 \cdot 0$ & $0.44 \pm 0.27 *$ & $1 \cdot 79 \pm 1 \cdot 84$ & $<0.001$ \\
\hline $\begin{array}{l}\text { (a) on pancreatic enzymes } \\
\text { (b) no pancreatic enzymes }\end{array}$ & $\begin{array}{l}69 \\
14\end{array}$ & $\begin{array}{l}12 \cdot 2 \pm 5 \cdot 9 \\
12 \cdot 6 \pm 5 \cdot 6\end{array}$ & $\begin{array}{l}1 \cdot 8-25 \cdot 0 \\
2 \cdot 3-22 \cdot 0\end{array}$ & $\begin{array}{l}1.02 \pm 0.82 \\
0.39 \pm 0.27^{*}\end{array}$ & $\begin{array}{l}2 \cdot 34 \pm 2 \cdot 18 \\
1 \cdot 80 \pm 2 \cdot 0\end{array}$ & $\begin{array}{l}<0.005 \\
<0.02\end{array}$ \\
\hline
\end{tabular}

*Significantly different from CF patients taking pancreatic enzyme $P<0.001$.

tP value by paired $t$ test of post-prandial rise in SCCA level.

Values expressed as mean \pm SD. 


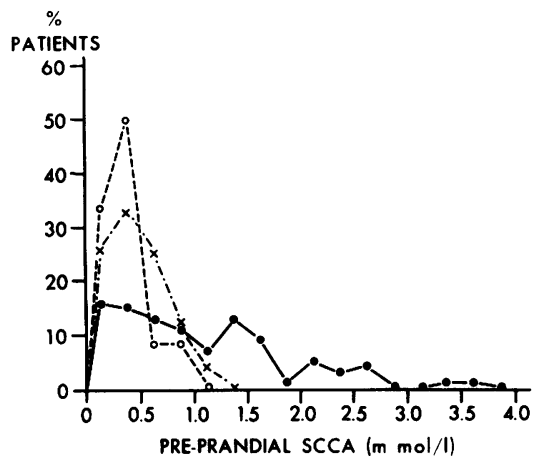

Fig. 1 Percentage distribution of pre-prandial SCCA values. $\times-\times$ controls, $\bigcirc-\bigcirc$ CF patients without steatorrhoea, $\longrightarrow$ CF patients with steatorrhoea.

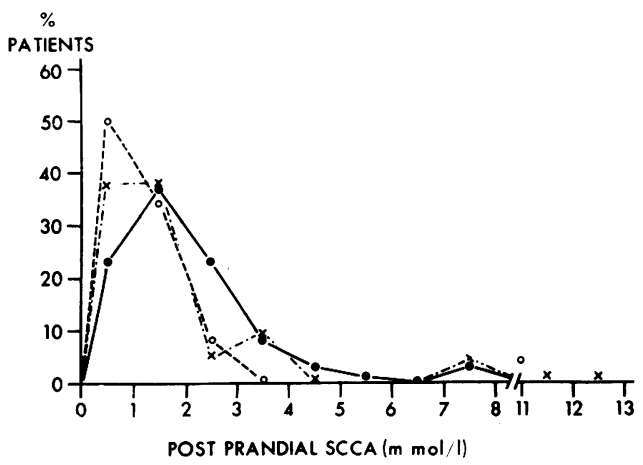

Fig. 2 Percentage distribution of post-prandial SCCA values. $\times-\times$ controls, $\mathrm{O}-\mathrm{CF}$ patients without steatorrhoea, $\longrightarrow C F$ patients with steatorrhoea.

with steatorrhoea exceeded this value. As can be seen clearly in Fig. 2, the range of post-prandial values increased markedly for all three groups, and it was not possible to draw a clear distinction between values in the CF group with steatorrhoea and the controls.

The significance of SCCA levels, both pre- and post-prandial, as an index of liver dysfunction within the group of CF patients receiving enzyme therapy is strengthened by the results shown in Table 3. Eighteen patients in this group had a palpable liver noted at the time of testing by an uninvolved physician who was unaware of the results of the assay. In this group of 18 patients, both fasting and post-prandial SCCA levels were significantly higher $(P<0.05)$ than in the group of 51 patients without a palpable liver. None of the 14 patients without steatorrhoea had a palpable liver.
Table 3 Palpable liver in 69 patients with steatorrhoea

\begin{tabular}{llll}
\hline & No. & \multicolumn{2}{l}{$S C C A($ mmol $l \pm S D)$} \\
\cline { 2 - 4 } & & Fasting & Post-prandial \\
\hline Palpable liver & 18 & $1.63 \pm 1.0$ & $3.73 \pm 3.36$ \\
Nonpalpable liver & 51 & $0.91 \pm 0.72$ & $1.86 \pm 1.3$ \\
& $P^{*}$ & $<0.05$ & $<0.05$ \\
\hline *Modified $t$ test for different sample variances (Nie et al. 1975).
\end{tabular}

None of the patients had an elevated direct or total bilirubin, while scattered abnormalities appeared in other tests. Mean values for albumin, $\gamma$ globulin, total protein, albumin:globulin ratio, AST, and ALP are shown in Table 4 for the two CF groups. AST values were significantly higher and albumin levels lower in the patients with steatorrhoea. Abnormal levels of all tests correlated poorly with high SCCA values however. Ten patients with steatorrhoea had AST values above the normal range. Of these, only six had elevated fasting SCCA levels. Eleven patients had serum albumin values lower than $38 \mathrm{~g} / \mathrm{l}$; of these, four had elevated serum SCCA levels. Of the 12 patients with high serum $\gamma$ globulin values (over $15 \mathrm{~g} / \mathrm{l}$ ), three had elevated fasting SCCA values ( $>3$ SD above mean). Five patients had ALP values greater than normal; of these, two had elevated fasting SCCA levels.

Table 4 Other putative tests of liver function in $C F$ patients with and without steatorrhoea

\begin{tabular}{|c|c|c|c|}
\hline \multirow[t]{2}{*}{ Serum values* } & \multicolumn{2}{|l|}{$C F$ patients } & \multirow[t]{2}{*}{$\mathbf{P}$} \\
\hline & $\begin{array}{r}\text { - steatorrhoea } \\
\text { (mea }\end{array}$ & $\begin{array}{l}+ \text { steatorrhoea } \\
\pm S D)\end{array}$ & \\
\hline $\begin{array}{l}\text { Albumin } \\
\gamma \text { globulin } \\
\text { Total protein } \\
\text { Albumin :globulin } \\
\quad \text { ratio } \\
\text { AST } \\
\text { ALP }\end{array}$ & $\begin{array}{c}46.3 \pm 3.6 \\
8.8 \pm 4.5 \\
71.8 \pm 6.8 \\
\\
1.93 \pm 0.51 \\
15.6 \pm 5.4 \\
180 \pm 110\end{array}$ & $\begin{array}{l}41.9 \pm 4.7 \\
10.4 \pm 6.7 \\
70.1 \pm 7.7 \\
\\
1.63 \pm 0.53 \\
20.9 \pm 8.8 \\
154 \pm 62\end{array}$ & $\begin{array}{l}<0.002 \\
\text { NS } \\
\text { NS } \\
\text { NS } \\
<0.05 \\
\text { NS }\end{array}$ \\
\hline
\end{tabular}

* Protein estimations are expressed as g/1 \pm SD, AST and ALP as $\mathbf{I U} / \mathbf{I} \pm \mathrm{SD}$.

Figure 3 presents the correlation matrix of a number of variables, including the results of tests of liver function, three pulmonary function tests, and age in the group of 52 patients taking pancreatic supplements who were old enough to have had pulmonary testing. None of the variables, including age, correlated with the SCCA levels, although the correlation coefficient for AST levels was higher than for other variables. A similar lack of correlation with other variables was found for the AST. On the other hand, both the $\gamma$ globulin and the albumin: globulin ratio correlated strongly with the three tests of pulmonary function, indicating that these 


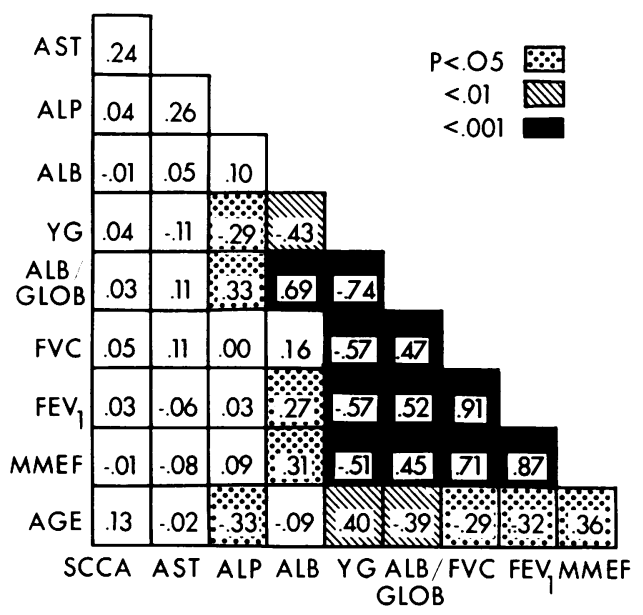

Fig. 3 Correlation matrix showing relationship between the biochemical tests, pulmonary function tests, and age in patients with steatorrhoea. Numbers in squares are positive and negative correlation coefficients. Clear squares indicate no significant correlation, shaded and cross-hatched squares indicate significant correlations. $A S T=$ serum aspartate amino transferase, $A L P=$ serum alkaline phosphatase, $A L B / G L O B=$ albumin:globulin ratio, $F V C=$ forced vital capacity, $F E V_{1}=1$-second forced expiratory volume, $M M E F=$ mean forced expiratory flow rate during the middle half of the FVC.

tests were more likely to reflect the course of pulmonary disease in these patients than disordered hepatic function. Serum albumin levels also correlated with two of the three tests of pulmonary function, suggesting a relatively close relationship to pulmonary disease. ALP, $\gamma$ globulin, albumin: globulin ratios, and pulmonary function were all affected by age, but when these parameters were adjusted for age by partial correlation analysis none correlated with either SCCA or AST levels.

\section{Discussion}

From the results of our study the fasting SCCA level appears to be more useful in discriminating between normal and abnormal liver function than the 2-hour post-prandial SCCA level. Studies of fasting and post-prandial serum bile acid levels in hepatobiliary disease by other workers have produced conflicting results with regard to which is the best discriminator ${ }^{3-5} 7$ Pennington et al. ${ }^{7}$ found fasting serum bile acids to be as sensitive in the detection of liver disease as the post-prandial values. However, Kaplowitz et al. ${ }^{3}$ and Barnes et $a l .{ }^{4}$ found the 2-hour post-prandial value more sensitive. It must be noted that, in these two studies, the method used was not able to detect a post-prandial rise in serum bile acids in normal patients. Fausa and Gjone, ${ }^{5}$ using a more sensitive technique, found that the size of the postprandial elevation of serum bile acids was a more sensitive indicator of hepatobiliary disease. However, none of these studies included patients with CF.

The rise in serum bile acids after a meal results from greatly increased absorption of bile acids which are presented to the intestine as a bolus following the emptying of the gallbladder. La Russo et al. ${ }^{15}$ have shown, with the use of a radioimmunoassay method, that after a meal there was a greater increase in SCCA levels in healthy subjects than in patients with cholecystectomy or ileal resection. More than $40 \%$ of patients with CF have anatomically or functionally abnormal gallbladders, ${ }^{16}$ and in these patients the size of the post-prandial bile salt bolus is likely to be greatly reduced. Watkins et al. ${ }^{17}$ demonstrated that while CF patients had increased bile acid loss in the stools, their ileal reabsorptive function for bile acids was normal when they were treated with pancreatic enzyme replacement. Since all of our patients with steatorrhoea were taking pancreatic supplements the failure of the post-prandial SCCA level to discriminate between normal and abnormal is more likely to be related therefore to a diminished post-prandial bile output than to diminished bile salt absorption. Cowan et al. ${ }^{18}$ have shown that the half-life of any bile acid in the blood is extremely short. In the presence of minimal absorption, as in the fasting state, plasma clearance by the liver becomes the most important determinant of SCCA levels. Since these levels are not affected by either gallbladder function or intestinal function it is perhaps not surprising that they are superior to post-prandial values in discriminating between patients with CF and steatorrhoea.

In the present study, $38 \%$ of the patients with steatorrhoea had high fasting SCCA levels, suggesting that approximately one-third of these patients had liver dysfunction. We did not feel justified in obtaining liver biopsies in otherwise asymptomatic patients, although the histology would have provided an independent index of abnormality with which these results can be compared. The design of the study also precluded BSP clearance estimations. The fact that patients with palpable livers had higher SCCA values is consistent, however, with the hypothesis that the test reflects significant liver dysfunction. Other studies also suggest a high incidence of liver dysfunction in CF. In a somewhat similar group of patients, Kattwinkel et al. ${ }^{19}$ found that $38 \%$ of their patients had high AST and liver 
alkaline phosphatase values. Oppenheimer and Esterley ${ }^{20}$ found that 20 to $25 \%$ of patients with CF had evidence of biliary cirrhosis at necropsy, although these changes were focal and not correlated with functional abnormalities.

SCCA levels appear to indicate liver dysfunction more sensitively than the AST, since 20 patients $(29 \%)$ with normal AST values had high SCCA values. On the other hand, only six of the 10 patients with elevated AST levels also had elevated SCCA values, indicating that the degree of correlation between these two putative liver function tests was not very great. With regard to other possible tests of liver function our data clearly show that the serum albumin, $\gamma$ globulin, and albumin:globulin ratio are of no value in assessing the frequency of liver disease in the $\mathrm{CF}$ population since they correlate so strongly with pulmonary function.

In contrast to the patients with steatorrhoea, the 14 patients without steatorrhoea had normal fasting SCCA, AST, ALP, and serum protein values. Thus evidence of liver dysfunction was restricted to patients with pancreatic insufficiency. It is premature, however, to suggest that pancreatic insufficiency might be causally related to liver dysfunction since patients without steatorrhoea tend to have a relatively mild pulmonary disease as well (Gaskin and Forstner, unpublished observations). The lack of hepatic dysfunction in these patients may therefore simply reflect a generally milder form of the disease.

Further studies are required to determine the usefulness of the immunoassay of SCCA in monitoring the progression of liver disease in patients with CF. It is unknown, for example, whether the test might return to normal with improvement in nutritional state, as one would expect of a transient steatosis, or how often liver dysfunction as measured by a single sampling of a large population may represent transient hepatic dysfunction secondary to pulmonary disease or treatment.

We thank Mrs A Madapallimatam for technical assistance and the Canadian Cystic Fibrosis Foundation for financial support.

\section{References}

${ }^{1}$ Simmonds WJ, Korman MG, Go VLW, Hofmann AF. Radioimmunoassay of conjugated cholyl bile acids in serum. Gastroenterology 1973;65:705-11.

${ }^{2}$ Korman MG, Hofmann AF, Summerskill WHJ. Assessment of activity in chronic active liver disease. Serum bile acids compared with conventional tests and histology. New Engl J Med 1974;290:1399-402.

${ }^{3}$ Kaplowitz N, Kok E, Javitt NB. Postprandial serum bile acid for the detection of hepatobiliary disease. J Amer Med Assoc 1973;225:292-3.
${ }^{4}$ Barnes S, Gallo GA, Trash DB, Morris JS. Diagnostic value of serum bile acid estimations in liver disease. J Clin Pathol 1975;28:506-9.

${ }^{5}$ Fausa $\mathrm{O}$, Gjone E. Serum bile acid concentrations in patients with liver disease. Scand J Gastroenterol 1976;11:537-43.

${ }^{6}$ Korman MG, LaRusso NF, Hoffman NE, Hofmann AF. Development of an intravenous bile acid tolerance test. Plasma disappearance of cholyglycine in health. New Engl J Med 1975;292:1205-9.

${ }^{7}$ Pennington CR, Ross PE, Bouchier IAD. Serum bile acids in the diagnosis of hepatobiliary disease. Gut 1977;18:903-8.

${ }^{8}$ Goodchild MC, Murphy GM, Howell AM, Nutter SA, Anderson CM. Aspects of bile acid metabolism in cystic fibrosis. Arch Dis Child 1975;50:769-78.

${ }^{9}$ Lloyd-Still JD, Demers LM. Serum bile acids in pediatric hepatic disorders. Gastroenterology 1976; 71 :919. (Abstract)

${ }^{10}$ Wormsley KG. The response to infusion of a combination of secretin and pancreozymin in health and disease. Scand J Gastroenterol 1969;4:623-32.

${ }^{11}$ Davidson GP, Koheil A, Forstner GG. Salivary amylase in cystic fibrosis. A marker of disordered autonomic function. Ped Res 1978;12:967-70.

${ }^{12}$ Sondheimer J, Bryan H, Andrews W, Forstner G. Cholestatic tendencies in premature infants, on and off parenteral nutrition. Pediatrics 1978;62:984-9.

${ }^{13} \mathrm{Nie} \mathrm{NH}$, Hull $\mathrm{CH}$, Jenkins JG, Steinbrenner K, Bent DH. Statistical package for the Social Sciences, 2nd ed. New York: McGraw-Hill Book Company, 1975.

${ }^{14}$ Snedecor GW, Cochran WG. Statistical Methods. 6th ed. Ames, Iowa: Iowa State Univ Press, 1967.

${ }^{15}$ LaRusso NF, Korman MG, Hoffman NE, Hofmann AF. Dynamics of the enterohepatic circulation of bile acids: postprandial serum concentrations of conjugates of cholic acid in health, cholecystectomized patients, and patients with bile acid malabsorption. New Engl J Med 1974;291:689-92.

${ }^{16}$ Isenberg JN, L'Heureux PR, Warwick WJ, Sharp HL. Clinical observations on the biliary system in cystic ñbrosis. Amer J Gastroenterol 1976;65:134-41.

17 Watkins JB, Tercyak AM, Szczepanik P, Klein PD. Bile salt kinetics in cystic fibrosis: influence of pancreatic enzyme replacement. Gastroenterology 1975; 68:1087. (Abstract)

${ }^{18}$ Cowan AE, Korman MG, Hofmann AF, Thomas PJ. Plasma disappearance of radio activity after intravenous injection of labeled bile acids in man. Gastroenterology 1975;68:1567-73.

${ }^{19}$ Kattwinkel J, Taussig LM, Statland BE, Verter JI. The effects of age on alkaline phosphatase and other serologic liver function tests in normal subjects and patients with cystic fibrosis. J Pediat 1973;82:234-42.

${ }^{20}$ Oppenheimer EH, Esterly JR. Hepatic changes in young infants with cystic fibrosis. Possible relation to focal biliary cirrhosis. J Pediat 1975;86:683-9.

Requests for reprints to: Dr GG Forstner, The Hospital for Sick Children, 555 University Avenue, Toronto, Ontario, Canada, M5G 1 X8. 